\title{
Changes in the biophysical properties and ultrastructure of lungs, and intrapulmonary fibrin deposition in experimental acute pancreatitis
}

\author{
A R BERRY, G C DAVIES, A M MILLAR, AND T V TAYLOR \\ From the University Department of Clinical Surgery, Royal Infirmary, Edinburgh
}

SUMmARY Using an experimental model of acute pancreatitis in the rat, we have studied changes in the biophysical properties of lungs and intrapulmonary fibrin deposition in this condition. Acute pancreatitis is associated with a significant decrease in pulmonary compliance $(\mathrm{p}<0.01)$ and a significant increase in lung weight $(\mathrm{p}<0.01)$ compared with a control sham operation group. These changes are associated with a $24 \%$ increase in intrapulmonary ${ }^{125}$ I fibrinogen deposition $(p<0.01)$, and an $18 \%$ increase in ${ }^{125}$ I fibrinogen deposition per gram of lung tissue $(p<0.05)$ in acute pancreatitis, compared with a control sham operation group. The increased fibrinogen deposition is abolished by treatment with low dose heparin. Using the same animal model changes in pulmonary ultrastructure are shown using scanning electron microscopy. The results indicate that pulmonary abnormalities are associated with intrapulmonary fibrin deposition in experimental acute pancreatitis and these findings may be relevant to the well described respiratory complications of the condition in man.

The importance of various respiratory complications which occur in patients with acute pancreatitis has been repeatedly emphasised ${ }^{1-6}$ since pleural empyema was first described in such a patient in 1932. ${ }^{7}$ Though several theories, including denaturation of surfactant ${ }^{89}$ and the development of arteriovenous shunts, ${ }^{10}$ have been suggested to explain these pulmonary abnormalities, the mechanism remains incompletely understood and probably involves many factors.

The clinical features are those of adult respiratory distress syndrome, ${ }^{11}$ a condition which has been attributed to intrapulmonary fibrin deposition. ${ }^{12} 13$ Coagulation disturbances, which occur in acute pancreatitis, ${ }^{61415}$ may contribute to the pulmonary damage in this condition.

$A$ better understanding of the mechanism involved is desirable to facilitate treatment and improve prognosis in this group of patients. Using a model of acute pancreatitis in the rat, we have studied the changes which occur in the biophysical properties of lung, in the ultrastructural pulmonary appearances and in intrapulmonary fibrin

Address for correspondence: Mr A R Berry, FRCS, John Radcliffe Hospital. Headington, Oxford OX3 9DU.

Received for publication 14 January 1983 deposition. The latter was measured using ${ }^{125} I$ fibrinogen injection.

\section{Methods}

\section{MATERIALS}

Adult Sprague Dawley rats weighing between $250 \mathrm{~g}$ and $350 \mathrm{~g}$ were fasted for 24 hours, but given free access to water and then anaesthetised using intraperitoneal pentobarbitone (Sagatal $60 \mathrm{mg} / \mathrm{ml}$ ) diluted to a $10 \%$ solution with ethyl alcohol, in a dose of $0.75 \mathrm{ml} / 100 \mathrm{~g}$ body weight. Acute pancreatitis was then induced as described by Chetty et al. ${ }^{16}$ This method involves forming a closed duodenal loop around a piece of fine plastic tubing which maintains intestinal continuity. Infected human $T$ tube bile is then injected into the loop with sufficient pressure to produce distension of the loop and reflux along the pancreatic duct. The model consistently produces a severe haemorrhagic form of acute pancreatitis.

\section{EXPERIMENT I}

Three groups of eight rats were studied. (1) sham gastrotomy - killed at six hours, (2) acute pancreatitis - killed at six hours, (3) acute pancreatitis - killed at 24 hours. 
In the sham operation group, laparotomy was performed under general anaesthesia, the stomach was opened, as for the passage of the plastic tubing, but then simply closed.

Immediately before death, at the predetermined time, blood was taken for serum amylase estimation (Phadebas technique) and rats were killed by administering a massive overdose of intraperitoneal pentobarbitone. After death the lungs were carefully removed and inflated with $10 \mathrm{ml}$ air and then deflated. Inflation/deflation pressures were measured at $0.5 \mathrm{ml}$ intervals using a three way tap and a water manometer as previously described. ${ }^{17}$ The lungs were then cleaned and weighed. Pulmonary compliance was calculated from the gradient of the curve obtained by plotting lung volume against intrapulmonary pressure, over the first $5 \mathrm{ml}$ of a slow deflation from a maximum inflation as recommended. ${ }^{18}$ In a further two rats in each of the above three groups, immediately after death the lungs were fixed for scanning electron microscopy by inflating them at a constant pressure ( $3 \mathrm{ml} \mathrm{H}_{2} \mathrm{O}$ ) with $2.5 \%$ glutaraldehyde in $0.1 \mathrm{M}$ cacodylate buffer ( $\mathrm{pH} 7 \cdot 4$ ). Blocks of tissue were then cut, completely dehydrated in increasing concentrations of acetone, and then critical point dried. The dried mounted tissue was then sputter coated with a thin layer $(20 \mathrm{~nm})$ of gold and examined in an ISI-60 scanning electron microscope (SEM) using an acceleration voltage of $30 \mathrm{kV}$. Many areas within each lung were examined to determine the overall condition of the alveoli and a few representative photographs were taken.

\section{EXPERIMENT 2}

Pulmonary fibrin deposition was studied using ${ }^{125} \mathrm{I}$ human fibrinogen injection in four groups of eight Sprague Dawley rats. This technique has previously been validated by Saldeen. ${ }^{19}$ (1) Sham gastrotomy, (2) acute pancreatitis, (3) acute pancreatitis plus heparin (50 IU/kg subcutaneously), (4) acute pancreatitis plus dextran ( $2 \mathrm{ml}$ intravenously).

Acute pancreatitis was induced as previously reported $^{16}$ and immediately after operation $0.05 \mathrm{mg}$ of iodinated $\left({ }^{125} \mathrm{I}\right)$ human fibrinogen injection (approximately $7 \mu \mathrm{Ci}$ ) in $\mathbf{0 . 2} \mathrm{ml}$ sterile water was injected into a femoral vein. In group 3 this was followed by $50 \mathrm{IU} / \mathrm{kg}$ heparin injected subcutaneously and in group 4 by $2 \mathrm{ml}$ dextran 70 injected into the opposite femoral vein. All rats were killed after six hours by the method previously described and the lungs were immediately removed, blotted dry, and weighed before counting in an LKB-Wallac 80000 gamma scintillation counter. Organ counting was performed relative to an ${ }^{125} \mathbf{I}$ standard (approximately $7 \mu \mathrm{Ci}{ }^{125} \mathrm{I}$ ) against which the injection had been counted. Statistical significance of the difference between the mean values of each group was calculated by Student's $t$ test.

\section{Results}

\section{EXPERIMENT I}

Mean serum amylase concentrations were $14140 \pm 3600 \mathrm{IU} / \mathrm{l}$ (SD) in control group (I) compared with $106400 \pm 79629$ IU/l $(\mathrm{p}<0.01)$ and $169400 \pm 59826$ IU/l $(p<0 \cdot 001)$ in pancreatitis groups (II) and (III) respectively.

The specific pulmonary compliance (compliance/g lung weight) was $0.79 \pm 0.08 \mathrm{ml} / \mathrm{cm} \mathrm{H}_{2} \mathrm{O} / \mathrm{g}$ in the sham operation group (I), compared with $0 \cdot 64 \pm 0 \cdot 11$ $\mathrm{ml} / \mathrm{cmH}_{2} \mathrm{O} / \mathrm{g}(\mathrm{p}<0.01)$ and $0.69 \pm 0.09 \mathrm{ml} / \mathrm{cm} \mathrm{H}_{2} \mathrm{O} / \mathrm{g}$ $(\mathrm{p}<0.01)$ in the pancreatitis groups (II) and (III) respectively (Fig. 1).

Lung weight (as a percentage of total body weight) was $0.34 \pm 0.03 \%$ in control group (I) compared with $0.49 \pm 0.13 \% \quad(p<0.01)$ and $0.42 \pm 0.07 \%(\mathrm{p}<0.01)$ in pancreatitis groups (II) and (III) respectively (Fig. 2).

Figures 3 and 4 show representative scanning electron micrographs of lung from the sham operation group and the pancreatitis group killed at

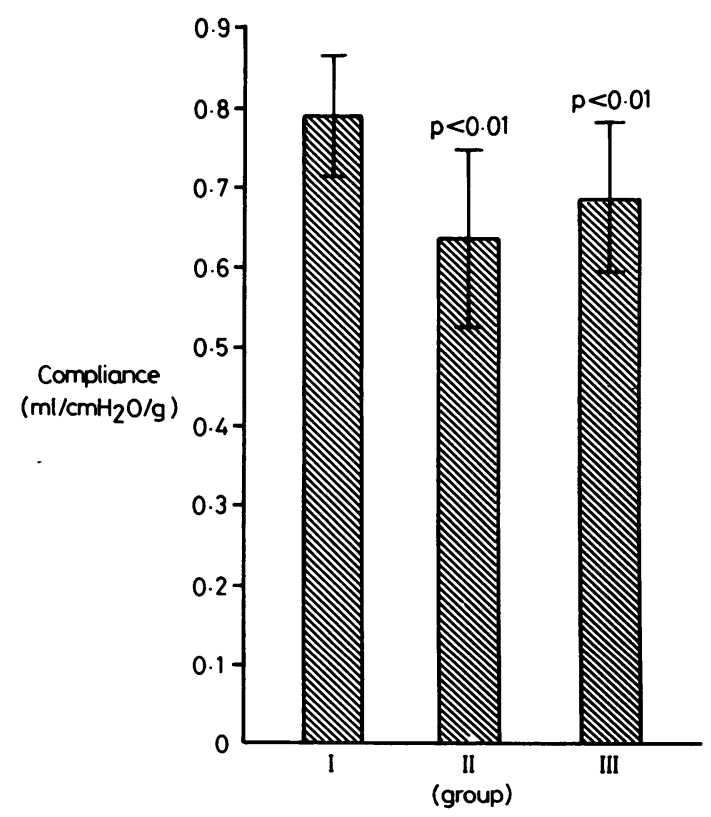

Fig. 1 Specific pulmonary compliance in control sham operation group (I) and pancreatitis groups at six hours (II) and 24 hours $(I I I)-($ mean $\pm S D)$. 


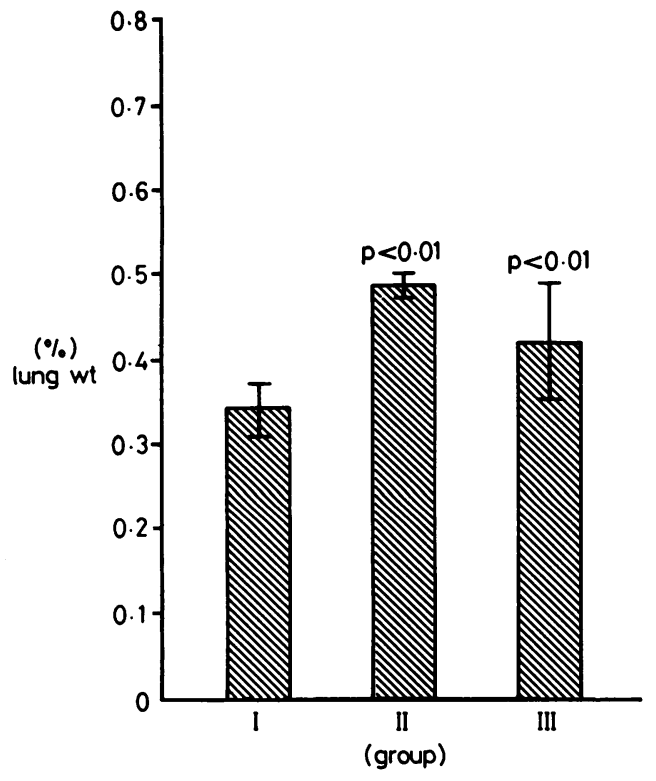

Fig. 2 Lung weight expressed as \% of total body weight in control sham operation group (I) and pancreatitis groups at six hours (II) and 24 hours (III) (mean $\pm S D$ ).

six hours and at original magnification of 2000 .

In the pancreatitis groups, gross distortion of alveolar architecture was seen. The type I pneumocytes which form the alveolar wall were contracted and the interalveolar septa had a crenated, thickened and irregular surface (Fig. 4) compared with the sham operated animals (Fig. 3). Though the mechanisms of these changes await further clarification, they were diffusely present throughout all sections of the lungs examined.

\section{EXPERIMENT 2}

The percentage of ${ }^{125} \mathrm{I}$ fibrinogen deposited in the lungs of the control group (1) was $1 \cdot 38 \pm 0.17 \%$ compared with $1.72 \pm 0.25 \%(\mathrm{p}<0.01)$ in the pancreatitis group (2). This $24 \%$ increase was abolished by treatment with a low dose of heparin (group 3) $(1.33 \pm 0.15 \%, \mathrm{p}<0.01)$ and by intravenous dextran 70 (group 4) $(1 \cdot 13 \pm 0 \cdot 1 \%, p<0 \cdot 001)$ (Fig. 5).

The percentage of ${ }^{125} \mathrm{I}$ fibrinogen deposited per gram of lung tissue was $0.9 \pm 0.09 \% / \mathrm{g}$ in the control group (1) compared with $1.07 \pm 0.18 \% / g$ in the pancreatitis group $(2)(p<0.05)$. This $18 \%$ increase was abolished by treatment with heparin in group 3 $(0.77 \pm 0.06 \% / g, p<0.01)$. Treatment with dextran 70 (group 4) did not significantly decrease ${ }^{125}$ I fibrinogen deposition per gram of lung tissue $(0.91 \pm 0.08 \% / g, p>0.05)$ (Fig. 6).

Three rats in group four died soon after administering the dextran 70 . This was attributed to dextran anaphylaxis a problem previously reported with Sprague Dawley rats. ${ }^{20}$ Because of their deaths the results with dextran are anomalous and difficult to interpret. They do, however, show a favourable trend and, therefore we feel they are worth reporting.

\section{Discussion}

The raised serum amylase concentrations in groups (II) and (III) in the first experiment confirm that the model used produces acute pancreatitis. Histological confirmation of this is seen in Figure 7 which
Fig. 3 Scanning electron micrograph of rat lung from sham operated animal (original magnification $\times 2000$ )

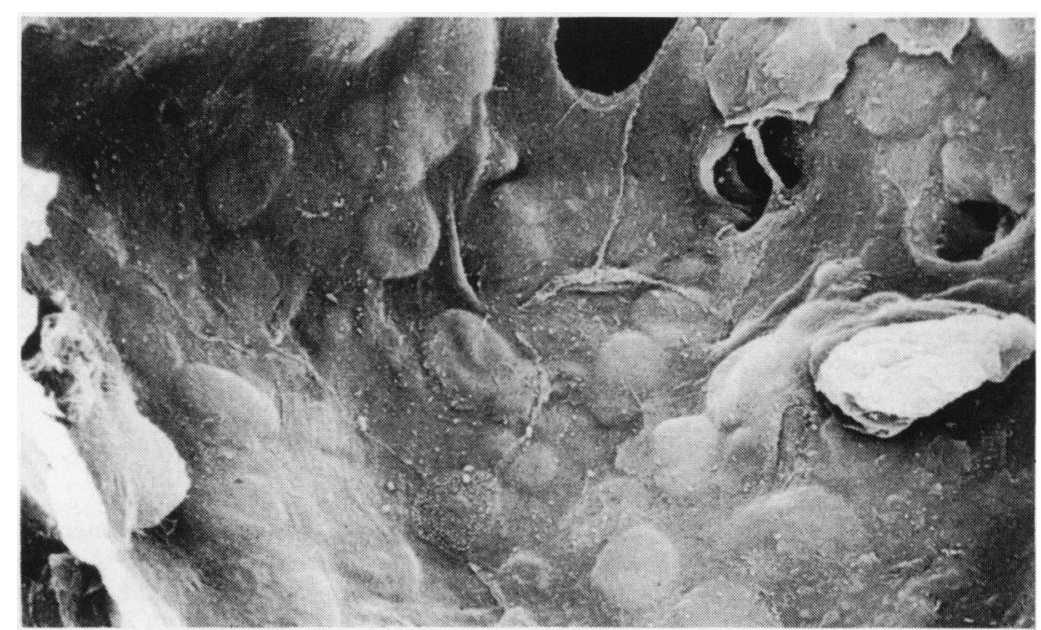


Fig. 4 Scanning electron micrograph of rat lung from pancreatitis group killed at six hours (original magnification $\times 2000$ ).

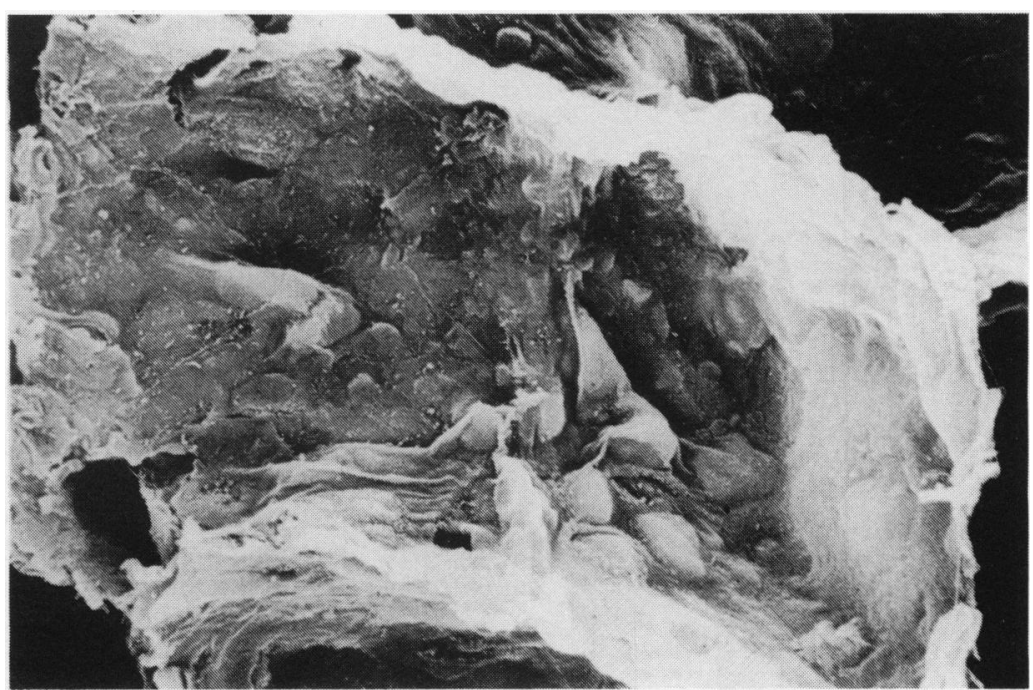

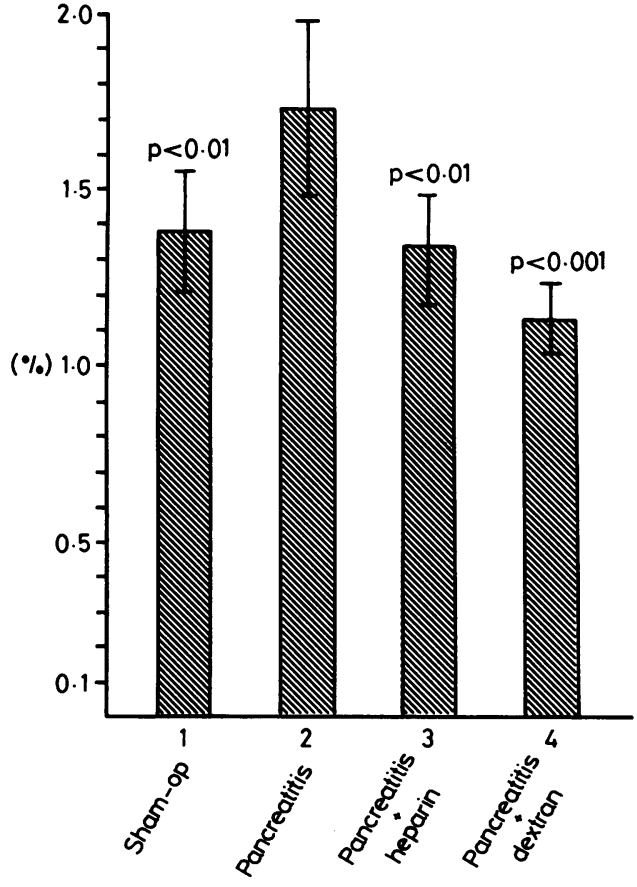

Fig. 5 Percentage of ${ }^{125}$ I fibrinogen taken up by lungs in sham operation group (1), acute pancreatitis group (2) and pancreatitis groups treated with heparin (3) and dextran 70 (4) (mean $\pm S D)$.

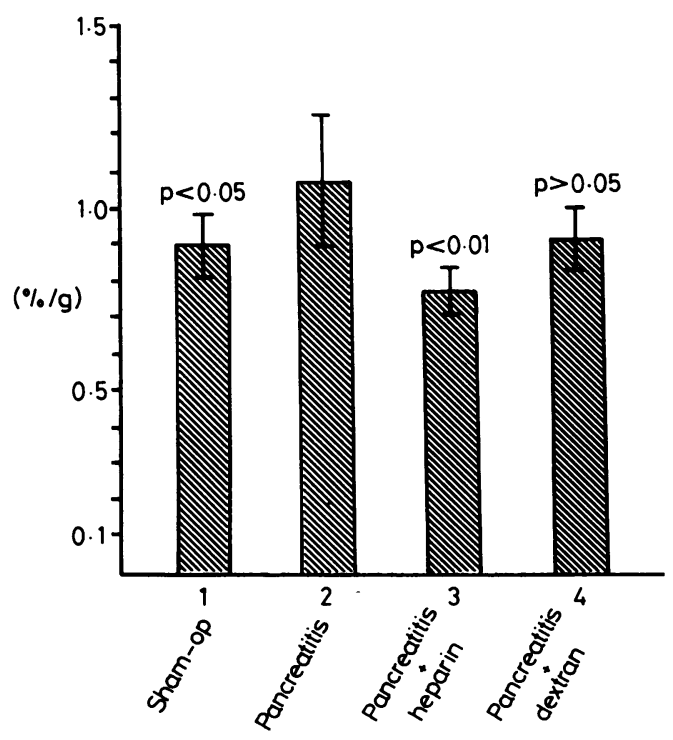

Fig. 6 Percentage of ${ }^{125}$ I fibrinogen taken up per gram of lung weight in sham operation group (1), acute pancreatitis group (2) and pancreatitis groups treated with heparin (3) and dextran $70(4)$ (mean $\pm S D)$. 
Fig. 7 Histological appearance of pancreatic tissue from rat subjected to pancreatitis model and killed at six hours (Haematoxylin + eosin, original magnification $\times 120$ ).

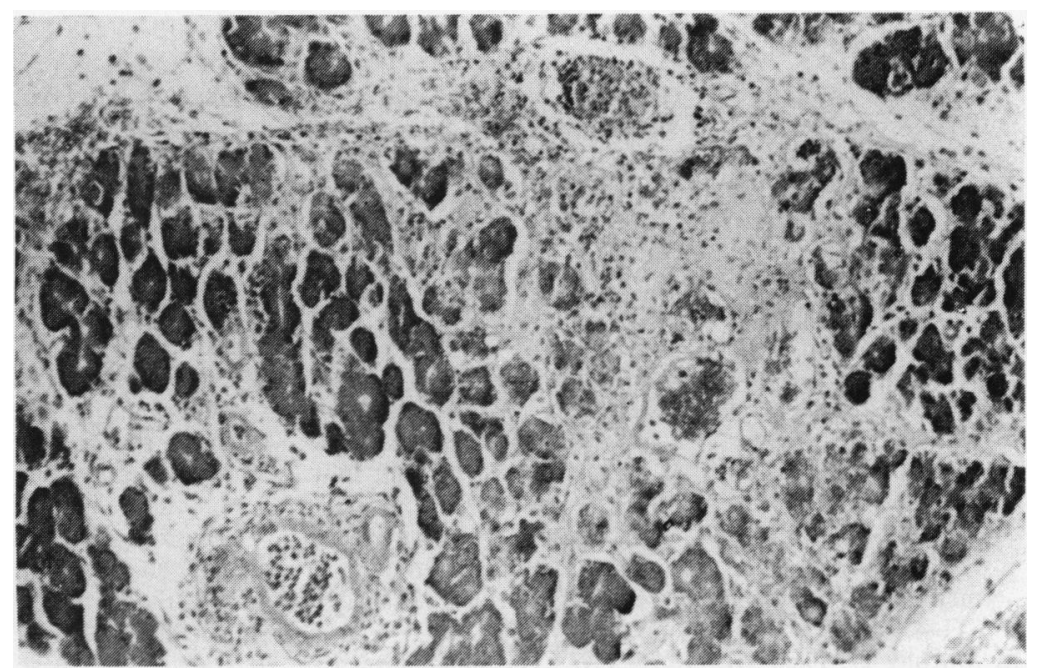

shows haemorrhage with intraductal and periductal abscess formation; and the appearances are consistent with acute haemorrhagic pancreatitis. A significant decrease in pulmonary compliance and an increase in pulmonary weight occurred at both six and 24 hours compared with the controls, with maximum changes occurring at six hours.

As pulmonary compliance depends on both the intrinsic elastic properties of the alveolar wall and surfactant, the decrease could be due to a reduction in the concentration of the latter factor alone ${ }^{89}$ The ultrastructural changes shown by SEM, however, suggest that the alveolar wall is morphologically altered in acute pancreatitis and particularly that the abnormalities occur diffusely throughout affected lungs. Though these changes are difficult to quantify the alveoli and pneumocytes undoubtedly appear contracted in the pancreatitis groups compared with the control group.

The results of the second experiment indicate that the changes are associated with intrapulmonary fibrin deposition, in that at 6 hours (when the changes in biophysical properties are maximal) there -was a significant increase in the uptake of ${ }^{125} \mathrm{I}$ fibrinogen in lungs in the pancreatitis group compared with the control group. This finding gives further credence to the view that acute pancreatitis produces the same pulmonary abnormalities that occur in adult respiratory distress syndrome. ${ }^{6}{ }^{11-13}$ How fibrin deposition produces the changes reported is open to debate, but it seems likely that the harmful effects are due to peptides released during the conversion of fibrinogen to fibrin ${ }^{21}$ or to the products of fibrin breakdown themselves. ${ }^{22} \mathrm{We}$ have previously shown that the degree of hypoxia in patients with acute pancreatitis correlates with plasma fibrinogen concentrations and also is associated with complicated disease ${ }^{6}$ Our results suggest that these patients might benefit from early treatment with low dose heparin or dextran. Though the experimental results with dextran were conflicting because of the anaphylactic problem, they do show a trend towards decreasing intrapulmonary fibrin deposition and are therefore worthy of note - particularly as dextran anaphylaxis in humans is relatively uncommon. Further studies are necessary to clarify this.

A R Berry performed this work while receiving a Wellcome Surgical Research Fellowship. We wish to thank Mr G P Smith and Dr A E Williams of the Teaching and Research Centre, Western General Hospital, Edinburgh, who performed the electron microscopy. We also wish to thank Professor A P M Forrest, University Department of Clinical Surgery, Royal Infirmary, Edinburgh, in whose department this work was performed.

\section{References}

1 Ranson HJC, Turner JW, Roses DF, Rifkind KM, Spencer FC. Respiratory complications in acute pancreatitis. Ann Surg 1974; 179: 557-66.

2 Imrie CW, Ferguson JC, Murphy D, Blumgart LH. Arterial hypoxia in acute pancreatitis. Br J Surg 1977; 64: $185-8$

3 Roseman DM, Kowlessar OD, Sleisenger $\mathrm{MH}$. 
Pulmonary manifestations of pancreatitis. $N$ Engl $J$ Med 1960; 263: 294-6.

4 Interiano B, Stuart D, Hyde RW. Acute respiratory distress syndrome in pancreatitis. Ann Intern Med 1972; 77: 923-6.

5 Kellum JM, DeMeester TR, Elkins RC, Zuidema CD. Respiratory insufficiency secondary to acute pancreatitis. Ann Surg 1972; 175: 657-62.

6 Berry AR, Taylor TV, Davies GC. Pulmonary function and fibrinogen metabolism in acute pancreatitis. $\mathrm{Br} J$ Surg 1981; 68: 870-3.

7 De Takats G, MacKenzie WD. Acute pancreatic necrosis and its sequelae. Ann Surg 1932; 96: 418-40.

8 Morgan AP, Jenny ME, Hassler H. Phospholipids acute pancreatitis and the lungs. Ann Surg 1968; 167: 329-35.

9 McIver AG, Metcalf IL, Ponmayer F, Harding PGR, Pasi RB. Alteration of surfactant chemistry in experimental haemorrhagic pancreatitis. J Surg Res 1977; 23: 311-4.

10 Murphy D, Pack AL, Imrie CW. The mechanism of arterial hypoxia occurring in acute pancreatitis. $Q J$ Med 1980; 49: 151-63.

11 Flenly DC. Clinical hypoxia, causes consequences and correction. Lancet 1978; 1: 542-6.

12 Blaisdell FW, Lim RC, Stallone RJ. The mechanism of pulmonary damage following traumatic shock. Surg Gynecol Obstet 1970; 130: 15-22.

13 Saldeen T. The microoembolism syndrome. Microvasc
Res 1076; 11: 227-59.

14 Shinowara GY, Stutman LJ, Walters MJ, Ruth ME. Walker EJ. Hypercoagulability in acute pancreatitis. Am J Surg 1963; 105: 714-9.

15 Kwaan HC, Anderson MC, Gramatica L. A study of pancreatic enzymes as a factor in the pathogenesis of disseminated intravascular coagulation during acute pancreatitis. Surgery 1971; 69: 663-72.

16 Chetty U, Gilmour HM, Taylor TV. Experimental acute pancreatitis in the rat - a new model. Gut 1980; 21: 115-7.

17 Berry AR, Taylor TV. Effect of drugs on the pulmonary changes in experimental acute pancreatitis in the rat. Gut 1982; 23: 481-4.

18 Mead J, Agostini E. Handbook of Physiology. Section 3 , chap 14, 445. Bethesda, Maryland: American Physiological Society.

19 Saldeen T. Quantitative determination of intravascular coagulation in lungs of experimental animals. Scand $J$ Haematol 1969; 6: 205-15.

20 Harris JM, West GB. Rats resistant to the dextran anaphylactoid reaction. $B r J$ Pharmacol 1963; 20: $550-62$.

21 Bayley T, Clements JA, and Osbahr AJ. Pulmonary and circulatory effects of fibronopeptides. Circ Res 1967; 21: 469-85.

22 Belew M, Gerdin B, Porath J, Saldeen T. Isolation of vasoactive peptides from human fibrin and fibrinogen degraded by plasmin. Thromb Res 1978; 13: 983-4. 